\title{
EL APORTE DE LAS NOCIONES DE CUERPOY EXPERIENCIA PARA LA COMPRENSIÓN DE LA "DISCAPACIDAD" COMO ASUNTO POLÍTICO
}

\author{
THE CONTRIBUTION OF THE NOTIONS OF BODY AND EXPERIENCE TO THE \\ UNDERSTANDING OF "DISABILITY" AS A POLITICAL ISSUE
}

\section{Carolina Ferrante ${ }^{1}$ y María PiaVenturiello²}

\begin{abstract}
Resumen:
El objetivo de este trabajo es proponer una conceptualización de la discapacidad como asunto político. Para ello, partiendo de los aportes del modelo social anglosajón, se sugiere que la incorporación de los conceptos de cuerpo y experiencia, originalmente exiliados del análisis en esta tradición de estudios, puede brindar elementos tendientes a iluminar los procesos de discriminación, exclusión y segregación que experimentan las personas con "discapacidad" en las sociedades occidentales contemporáneas. El texto se compone de tres partes. En un primer momento se caracteriza el modelo social de la discapacidad. En un segundo momento, se describe la exclusión del cuerpo y su necesaria dimensión política. Asimismo, se analiza el exilio de la experiencia al interior del modelo social y se plantea la necesidad de recuperar esta dimensión para potenciar la comprensión de la discapacidad como relación de dominación. Finalmente se elaboran unas reflexiones tendientes a discutir los límites y aperturas del modelo social para pensar la discapacidad en nuestros contextos latinoamericanos.
\end{abstract}

\section{Palabras clave:}

Modelo social de la discapacidad, DisabilityStudies, cuerpo, experiencia.

\begin{abstract}
:
The aim of this paper is to propose a conceptualization of disability as a political issue. To do this, based on input from the AngloSaxon social model, it is suggested that the incorporation of the concepts of body experience, originally exiles analysis of studies in this tradition, may provide elements intended to illuminate the processes of discrimination, exclusion and segregation experienced by people with "disabilities" in contemporary Western societies. The text consists of three parts. At first the social model of disability is characterized. In the second stage, the exclusion of the body is described, its necessary political dimension. Also, the exile experience within the social model is analyzed and a need to recover this dimension to enhance understanding of disability as a relationship of domination. Finally some thoughts tending to discuss the limits and starts to think of the social model of disability in our Latin American contexts are elaborated.
\end{abstract}

\section{Key-words:}

social model of disability, Disability Studies, body, experience.

1 Lic. en Sociología, Dra. en Ciencias Sociales por la Universidad de Buenos Aires. Inv. Postdoctorado CONICYT-FONDECYT (Proyecto 3140636), Universidad Católica del Norte. Av. Balmaceda 1504, 1408, Calama, Chile. (13900000). caferrrante@gmail.com

2 Lic. en Sociología, Dra. en Ciencias Sociales por la Universidad de Buenos Aires. Becaria Post-doctoral CONICET, Instituto de Investigaciones Gino Germani, Universidad de Buenos Aires. Pte. Uriburu $9506^{\circ}$ piso, Ciudad Autónoma de Buenos Aires, Argentina, (1114AAD). (+54 11) 4508.3815. venturiello@yahoo.com.ar 


\section{INTRODUCCIÓN}

Cuando hablamos de discapacidad, desde el sentido común, parecería que haríamos necesariamente referencia al lenguaje de lo biológico o de lo médico. La discapacidad, automáticamente, parecería llevarnos al ámbito de la falla, la falta, la "anormalidad". Y estas imágenes asociativas no sólo significan clasificaciones de funciones corporales, sino que van acompañadas de enunciados que cristalizan emociones negativas hacia esas particulares formas corporales. Es decir, no sólo tendemos a pensar a la discapacidad como una deficiencia corporal, sino que la comprendemos como una experiencia dolorosa e indeseable. De hecho, es habitual oir personas sin discapacidad que dicen "preferir morir" a vivir con una discapacidad, o, cuando se anuncia la llegada de un bebé en una familia, la mayoría de los allegados señalan el deseo de que el mismo "sea sanito". La vida con una discapacidad parecería ser una vida que no merecería ser vivida, una existencia no plenamente humana (Goffman, 2001).

Quizá, uno de los ámbitos sociales en que mejor veamos reproducida esta peculiar visión sobre la discapacidad sea en las campañas televisivas de las Teletones latinoamericanas. Las mismas-inspiradas en la Telethon norteamericana creada por Jerry Lewis en 1966-, transforman a los cuerpos de niños y niñas con deficiencias "en esencia y símbolo de la invalidez social" (Hervey citado en Haller, 2010: 139). En esta transmutación emergen los dos elementos que describíamos anteriormente: la discapacidad es reducida a un problema corporal, (en el que la sociedad parecería no tener injerencia), y, es calificada como una tragedia personal (Oliver, 1998), tributaria de caridad social y ayuda médica. Así, a través de la rehabilitación y recuperación de un funcionamiento corporal "normal", se alcanzaría una vida plena, digna de ser vivida (Haller, 2010).El restablecimiento de un desarrollo corporal e intelectual considerado biomédicamente "sano", se plantea como la llave para recuperar la humanidad perdida (Wilson, 2004; Joly, 2007).
Sociológicamente, esta mirada sobre la discapacidad -que no es la única pero sí es la dominante en la actualidad-, no puede ser tomada como algo únicamente biológico y necesariamente penoso. Esta peculiar visión es una expresión de los modos socialmente construidos e históricos de percibir los cuerpos en general y a esos etiquetados como "discapacitados", "deficitarios", o "con discapacidades" en particular, estableciendo diferentes estrategias para dar respuesta a la disponibilidad de las energías corporales singulares (Scribano, 2009). Y es por esto que las discapacidades, las deficiencias y las emociones que despiertan son cuestiones políticas, en tanto aluden a la estructuración general del poder (Scribano, 2009).

Plantear a la discapacidad como un asunto político implica necesariamente hacer alusión a al campo disciplinar de los Disability Studies, pioneros en sistematizar el abordaje social. Los Disabilitys Studies, que vincularon las luchas por los derechos de las personas con discapacidad con la teoría marxista, establecieron un origen estructural a la noción de discapacidad. Los autores de esa corriente (Filkeinstein, 1980, Oliver 1990, 1998, Barton, 1998) tienen el mérito de haber planteado a la discapacidad como una forma de opresión social, designándola como la causante de las desigualdades que padecen las personas en esta condición, oponiéndose a las teorías que la entienden como un problema individual. Esta postura, que entraña un giro teórico, fue propiciada por un nuevo posicionamiento político de las personas con discapacidad.

Si observamos los datos arrojados por el Informe Mundial de la Discapacidad, elaborado por la Organización Mundial de la Salud (OMS) y el Banco Mundial (BM) en el 2011 podemos notar la persistencia de diversas formas de exclusión que afectan a las personas con discapacidad. De acuerdo al mismo, del 15\% de población global que posee alguna discapacidad, un $80 \%$ de ellas es pobre, poseen peores resultados académicos, menor participación económica y cultural, mayor dependencia, peor salud que la población sin discapacidad. Estos procesos regresivos, especial- 
mente observables en contextos periféricos como el latinoamericano, no pueden ser leídos en forma aislada a toda una serie de indicadores negativos generados por el capitalismo actual: precarización del trabajo, flexibilización, desocupación, desigualdad, retroceso del Estado en el bienestar de la población (Castel, 1997). En un contexto darwinianamente competitivo la discapacidad deviene más que nunca factor de producción de diversas formas de vulnerabilidad social (Vite Pérez, 2012). Y en este sentido, el diagnóstico del modelo social anglosajón para explicar el por qué de la exclusión de las personas con discapacidad parece más atinado que nunca.

A través de este texto nuestra intención reside en señalar la pertinencia de recuperar una lectura sociológica de los conceptos cuerpo y experiencia para potenciar la capacidad crítica del modelo social de la discapacidad y superar algunas de las limitaciones indicadas en el mismo en las últimas dos décadas (Hughes y Paterson, 2008; Shakespeare y Watson, 2005; Corker, 2008; Ville et al, 2014). Partiendo de los aportes de autores enmarcados dentro del propio modelo social y un conjunto heterodoxo de autores provenientes de la sociología intentaremos mostrar tal pertinencia teórica.

Para este fin, seguiremos una estructura argumentativa compuesta de tres partes. En la primera parte caracterizaremos el modelo social anglosajón, definiendo su peculiar concepción de la discapacidad como forma opresiva. La segunda parte se compone de tres momentos: primero, describimos el exilio del cuerpo en el interior del modelo social; luego, planteamos las potencialidades de su re-incorporación, señalando cómo el cuerpo deficitario permite poner en escena toda una serie valores sociales históricos que fundan a la discapacidad como relación de dominación; finalmente analizamos la exclusión de la experiencia de la discapacidad y la necesidad de reintroducirla para analizar a la misma en términos relacionales. En la tercera parte, elaboraremos algunas reflexiones finales tendientes a señalar las potencialidades del modelo social a la luz de la incorporación de estas nociones, y, otros caminos también necesarios de ser pensados para analizar la discapacidad en la actualidad especialmente en contextos como el latinoamericano.

\section{El modelo social anglosajón y la discapacidad como forma opresiva}

Hacia la década de 1970, surgen los Disability Studiesjunto con el movimiento por los derechos de las personas con discapacidad anglosajón. Se trata de un grupo heterogéneo de estudios sociales, históricos y literarios tendientes a comprender a la discapacidad como retórica cultural (Skliar, 2002). En efecto, estos estudios constituyen una vertiente teórica de referencia para quienes se interesan por el tema de la discapacidad. Los autores lograron plasmar en sus escritos una mirada original que estaba revelándose en diferentes partes del mundo en torno de la discapacidad y que en la actualidad disputa mayor presencia desde la perspectiva de derechos. Por ejemplo, tanto en Argentina como en Brasil, desde los años 70, se observan protestas de colectivos de personas con discapacidad por la conquista del derecho a trabajar, la accesibilidad y la autonomía (Bregain, 2013). Cabe destacarse que en Argentina, la lucha del Frente Lisiados Peronistas por el derecho al trabajo y la vivienda, fue disruptiva al desafiar la lógica de reclamos aislados según patologías y aunarse detrás del reclamo de derechos reuniendo a personas con diferentes afecciones. (Joly y Venturiello, 2012).

Ahora bien, los supuestos e implicancias que subyacían a estas praxis, fueron analizados, desarrollados y explicitados en el ámbito académico por los Disability Studies. De allí, que se los considere pioneros de una mirada crítica de la discapacidad y la expresión teórica de un movimiento que hoy sigue su desarrollo. Aquí los retomamos puesto que esta perspectiva reunió la teoría con la práctica militante y buscó interpretaciones acerca de por qué la discapacidad no era reducible a su dimensión corporal ni médica, sino que constituía una forma de opresión. 
Los Disability Studies, a partir de la incorporación de los planteos desarrollados en los años 60 por Erving Goffman en torno a la construcción social del estigma y por Robert Scott en relación a la fabricación por parte del saber médico de la dependencia de las personas con discapacidad, se desarrollarán en ambas orillas del mundo anglosajón, aunque privilegiando diferentes aspectos de la discapacidad en tanto modo opresivo (Ville et al, 2014; Barnes, 1998). En el mundo norteamericano lo hará con atención a los aspectos culturales, mientras que en el área de Reino Unido lo realizará con interés por una lectura económica de la discapacidad, a partir de la incorporación de los aportes del materialismo histórico. Estos últimos darían origen a eso que Mike Oliver Ilamaría el modelo social de la discapacidad (Barnes, 1998). El mismo comprendería a la discapacidad ya no como una cuestión individual (médica y/o de la caridad), sino como una forma de exclusión, segregación y opresión generada por la sociedad capitalista (Oliver, 1998). Sin embargo, este ejercicio analítico llevaría a excluir las nociones de cuerpo y experiencia al comprender que estos elementos biologizaban y psicologizaban la discapacidad, invisibilizando su carácter político.

Aquí proponemos un esquema con los aportes teóricos fundacionales de losDisabilityStudies en su versión materialista de mayor peso, marcando la centralidad de tres construcciones conceptuales: a) la distinción entre deficiencia y discapacidad; b) la distinción entre el modelo médico y el modelo social yc) la vinculación de la discapacidad con el modo de producción capitalista.

Una de las principales características de los estudios sajones es la distinción entre la deficiencia y la discapacidad. La primera responde al orden biológico y no implica ninguna connotación negativa sino a partir de una estructura social quela convierte en discapacidad. Así la discapacidad se define como:

la desventaja o la restricción de la actividad causadas por una organización social contemporánea que no atiende, o atiende muy poco, a las personas que tienen insuficiencias físicas, y de este modo las excluye de las actividades sociales dominantes (UPIAS, 1976:3 en Abberley, 1998)

Es decir que, según esta definición, la deficiencia física no es lo que les impide trabajar, estudiar, tener una vida social plena, sino un orden social que limita sus derechos en pos de la normalización requerida para la producción moderna. La discapacidad es concebida, entonces, como una forma de discriminación: una construcción social que genera desventajas a una parte de la población con algún tipo de impedimento físico, cuyas necesidades específicas no son contempladas. Esta distincióndiscapacidad y deficiencia, al poner énfasis en la determinación de lo contextual, condujo a que el cuerpo, como categoría de análisis, haya sido tardíamente abordado por la sociología de la discapacidad. Sin embargo, no podemos dejar de observar que sosteniendo esta distinción analítica, desde sus orígenes las producciones del modelo brindaron elementos para desnaturalizar la deficiencia y eso Ilamado cuerpo capaz.Así, la expulsión del cuerpo del modelo social, obedece más a la necesidad de afianzar la dimensión social de la discapacidad. En efecto, pueden rastrearse menciones a la necesidad de cuestionar la categoría de deficiencia en varios escritos. Barnes (1998) se refiere a la construcción del mito de la "perfección corporal" y el ideal de "cuerpo capacitado" como resultados de las fuerzas materiales y culturales que general al opresión de las personas con discapacidad. Para lograr una teoría completa de la discapacidad, Abberley (1998) señala la importancia de encontrar el modo de incorporar la realidad material de la insuficiencia. Es decir, que el énfasis puesto en lo social es parte de la construcción de una teoría que busca presentar las causas de la opresión, a partir de incorporar las dimensiones cultural, política y económica hasta el momento desestimadas, que, no obstante, no debiera redundar en ignorar la experiencia encarnada.

Acerca de la distinción entre el modelo médico y el social, entendemos que se basa en una 
clasificación sobre los diferentes modos concebir la discapacidad a lo largo del tiempo y susideasdominantes. Así, se señala la discapacidad como "tragedia personal", "castigo divino" y como problema médico para luego mostrar su interpretación desde el modelo social(Oliver, 1998; Barnes, 1998). De este modo, las lecturas biologicistas e individualistas de la discapacidad quedaron nombradas bajo la titulación "modelo médico". Para construir la identidad un modelo social en oposición a un modelo médico, los autores se distanciarondetodo aquello que pudiera interpretarse como una lectura biológica de la discapacidad. Este enfoque era considerado como el soporte ideológico del sufrimiento de muchas personas, por llevarlas a un lugar de pasividad, inercia social y pérdida de autonomía. Así, se consolidó en esta perspectiva que las ideas surgidas desde el campo de la práctica médica y la rehabilitación subsumían a las personas en el "rol del enfermo" (Parsons, 1984). Las nociones de normalidad y corrección de los cuerpos tenían un asidero práctico en las instituciones de rehabilitación, las cuales el modelo social buscaba deconstruir y erradicar. Para lograrlo, como se menciona en el punto anterior, su primer posicionamiento teórico, fue distinguir al cuerpo de la sociedad que lo discapacita (Joly, 2008). De este modo, el objeto de estudio de los DisabilityStudies, en tanto modelo social que no reincidiría en los errores del modelo médico, era buscar las causas sociales de la discriminación a las personas con discapacidad. Mientras acusaban a la mirada médica de responsabilizar al individuo de su condición desviada, el modelo social se ocuparía de desentrañar cómo la sociedad impedía llevar una vida plena a los portadores de cuerpos deficientes. Al enfatizar este aspecto, se postergó la recuperación del cuerpo como territorio moldeable por los hábitos y representaciones sociales. La asimilación casi directa entre cuerpo, biología y modelo médico de la discapacidad, tendió a desdibujar la experiencia.

El último elemento que destacamos del modelo social de la discapacidad es la explicación materialista que ofrece. Es decir, existen tantas interpre- taciones del componente social de discapacidad, como miradas sobre las sociedades. Así, los aportes más originales de los estudios sajones se refieren a la incorporación de la lectura marxista en la interpretación de la discapacidad. Hasta el momento no se habían trazado relaciones históricas entre el desarrollo de las fuerzas productivas y las condiciones de vida de las personas con discapacidad. Hacia esa dirección se condujo el análisis de Oliver (1998), quien planteó que aunque siempre existieron personas con deficiencias, la concepción de la discapacidad surge con las labores de la industrialización, en las cuales el modelo de producción del hombre debe ajustarse, cada vez en mayor medida, a los tiempos estandarizados de las máquinas. En estas circunstancias, las personas con discapacidad sufrían desventajas respecto de las demás personas, ya que encontraban más dificultades para realizar las mismas tareas. Lo que en las sociedades precapitalistas causaba una disminución de los ingresos, en la etapa inicial de la industrialización fue motivo de completa exclusión. La producción artesanal, que se acomodaba a los tiempos de cada individuo, quedó atrás para desventaja de muchos, especialmente para aquellos que difícilmente podían imprimir a sus trabajos la creciente velocidad requerida por el capitalismo. Como resultado de ello, la discapacidad se vincula a la exclusión de las personas del sistema productivo que no se ajustan alas disposiciones corporales asociadas a criterios de rentabilidad económica. Con respecto de la vigencia de este pensamiento, el sociólogo argentino Eduardo Joly (2008) alude con ironía al incumplimiento del "derecho a ser explotados" de las personas con discapacidad y señala que, en caso de obtener trabajo, el mismo suele tener peores condiciones laborales y menor remuneración que el que obtienen las personas sin discapacidad. De allí que las estrategias de supervivencia de las personas con discapacidad debe estar ligada, en primer lugar, a la ayuda de sus familias, pese a la situación de escasez económica que puedan atravesar por la ausencia del ingreso que aportaría el adulto con discapacidad y por los gastos de su atención y cui- 
dado; en segundo lugar, esas estrategias pueden basarse en las prestaciones sociales del Estado y, en tercer término, a la caridad de instituciones y a la limosna (Joly, 2008).

Si bien este abordaje da cuenta de las condiciones materiales de existencia de las personas con discapacidad, una lectura unilateral de esta propuesta puede conducir a reduccionismo. Los análisis macrosociales que invisibilizan al cuerpo, dejan de lado otras formas de estratificación social que deterioran las condiciones de vida de las personas con discapacidad, como el género y la etnia (Shakespeare, 1998; Hanna y Rogovsky, 2008). Todos estos aspectos, pueden visibilizarse si se recupera a la experiencia de la discapacidad, como dimensión en la que se condensan diferentes tipos de inequidades y formas de dominación.

En suma, es de destacar, que mediante las interpretaciones señaladas, que retoman una teoría social crítica, el modelo social anglosajón plantea a la discapacidad como una forma de opresión social (Oliver, 1998, Abberley, 2008), designándola como la causante de las desigualdades que padecen las personas en esta condición. Este cambio, fue propiciado por un nuevo posicionamiento político por parte de las personas con discapacidad. Tal colectivo irrumpió enla esfera pública y cuestionó su marginación social como la principal generadora de las desventajas que enfrentan. En la comunión entre el movimiento por los derechos de este colectivo y los nuevos desarrollos conceptuales se gestó una forma de investigación al servicio de la emancipación de las personas con discapacidad (Oliver, 1998). Sin embargo, existieron cuestionamientos que condujeron a reformulaciones y una mayor complejización del modelo social de la discapacidad que se apoyan en diferentes puntos. Uno deellos es el formulado por Abberley (2008) ante la falta de precisión en el uso del concepto de opresión. El uso de este término, como sinónimo de explotación, constituye un equívoco en tanto limita su potencialidad para explicar relaciones de dominación que no resultande la lucha de clases. Por el contrario, una teoría de ladiscapacidad en tanto opresión supone poder captarlas diversas formas en que la sociedad puede generar dominación y, en tal sentido, producir la discapacidad. Esto implica señalar las diferencias en sus vidas de acuerdo a sus sectores sociales de pertenencia y explicar las condiciones materiales que generan estereotipos a partir de los cuales son marginados. En estesentido, el lugar de la opresión de la discapacidad es el cuerpo. Aquello que se impide hacer a esos cuerpos, como las "violaciones y prácticas esclavizantes" (Abberley, 2008) que se ejercen sobre ellos, configura la manera de vivir la opresión de las personas con discapacidades.

\section{Dos exiliados del modelo social de la discapacidad: el cuerpo y la experiencia}

\subsection{La deficiencia: ¿nada corporal?}

Como hemos visto, la operación metodológica establecida por el modelo social anglosajón para señalar el carácter opresivo de la discapacidad en las sociedades capitalistas residía en distinguir deficiencia y discapacidad (Shakespeare, 2013). En virtud de que se pensaba que la discapacidad era una imposición social impuesta sobre las personas con deficiencias, se consideraba que la discapacidad nada tenía que ver con el cuerpo (Hughes y Paterson, 2008). Las personas eran "discapacitadas" por algo externo a ellas: una sociedad que no los tenía en cuenta (Joly, 2008). De esta raíz, inclusive, nacía la preferencia por hablar de personas "discapacitadas", antes que de personas con "discapacidad", para enfatizar cómo las estructuras sociales son las que generan la opresión de este grupo (Shakespeare, 2013).

Si esta mirada permitió cuestionar visiones médicas de la discapacidad, promoviendo una concepción política de la misma, a la vez, esta distinción introduciría en el modelo algunas oposiciones dicotómicas propias del pensamiento social moderno. Es decir, el binomio deficiencia/ discapacidad, útil en términos de "toma de conciencia", incorporó el problema de pensar en 
términos antagónicos "lo biológico de lo social", el individuo de la sociedad, "el cuerpo de la sociedad", el cuerpo de la mente, lo médico de lo político, el dolor de la opresión, el modelo médico del modelo social, las personas "discapacitadas" de las personas sin discapacidad, lo subjetivo de lo objetivo (Hughes y Paterson, 2008: 113; Shakespeare, 2013; Ville et al, 2014).

Tal como señalan desde el interior del propio modelo social autores como Bill Hughes y Kevin Paterson (2008) y Tom Shakespeare y Nicholas Watson (1996) uno de los mayores éxitos del mismo, fue cuestionar el vínculo entre el cuerpo y la discapacidad, para indicar que la real fuente de la misma se encontraba en factores extra-médicos (Hughes y Paterson, 2008: 110). Sin embargo, al partir de una concepción biologicista del cuerpo se naturalizó a la deficienciacomo algo "dado" y no relevante en la experiencia opresiva de la discapacidad (Shakespeare, 2013; Hughes y Paterson, 2008). Desaparecidas las barreras sociales impuestas a las personas "discapacitadas", principalmente a través de la construcción de un mundo libre de las mismas y de la inclusión a través del trabajo, la deficiencia no significaría ningún problema en sí mismo (Shakespeare, 2013; Anastasiou y Kauffman, 2013).

La paradoja de esta mirada es que al valorar exclusivamente los aspectos económicos y estructurales que fundan en las sociedades capitalistas la segregación y distintas formas de exclusión de las personas "discapacitadas", con el fin de disputar simbólicamente las respuestas meramente caritativas y médicas, se reproducía una mirada del cuerpo y de la deficiencia biomédica. Dicho de otro modo, la lucha simbólica contra el Ilamado modelo médico rehabilitador, a partir de la definición de deficiencia asumida aceptaba la reducción del cuerpo a un mero conjunto de órganos, límite del individuo (Bourdieu, 1999).

En el modelo social se representa al cuerpo como sinónimo de su impedimento o disfunción física. Es decir, se lo define, al menos de manera implícita, en términos puramente bio- lógicos. No tiene historia. Es una esencia, un soporte atemporal y ontológico. Por lo tanto, el impedimento tiene un carácter opuesto al de la discapacidad: no es un producto social (...). [El modelo social] también propone un cuerpo carente de significado, una masa anatómica, corpórea y con disfunciones, inflexible en su resistencia a la significación y fenomenológicamente muerta, sin intencionalidad ni capacidad de acción(Hughes y Paterson, 2008, p. 111).

Renunciar a deconstruir aquello definido como deficiencia constituye una elección que implica resignar quizá la apuesta más provocadora del modelo social de la discapacidad: su propuesta de pensar a la misma como una construcción sociopolítica.Como hemos señalado en el apartado anterior, esta problematización no ha estado del todo ausente en el modelo social de la discapacidad, aunque no ha sido hasta hace dos décadas cuando se ha empezado a pensar la necesidad de incorporar aportes de otras áreas de las ciencias sociales, como por ejemplo, la sociología del cuerpo (Hughes y Paterson, 2008).

Precisamente, si tomamos los aportes que desde la sociología y la antropología analizaron el cuerpo podremos ver que no es posible reducir al mismo únicamente a su expresión biológica. Tal como señaló Marcel Mauss (1979) fundacionalmente en este ámbito de estudios el cuerpo es un producto social, el primer instrumento a partir del cual los grupos humanos transmiten los arbitrarios culturales que garantizan la reproducción social. Así, en los modos de usar el cuerpo, de presentarlo y de percibirlo, toda la cosmología política de un orden social se encuentra expresada(Mauss, 1979; Bourdieu, 1991).Desde esta perspectiva, todas las propiedades corporales -deseadas o rechazadas- están vinculadas a la división sexual y social del trabajo, y, por tanto atravesadas por relaciones de dominación históricas y acotadas (Bourdieu, 1991).

Específicamente respecto a la deficiencia y la discapacidad, al interior de la sociología, un trabajo como Estigma. La identidad social deteriorada, 
de ErvingGoffman, de 1963, (e inclusive fundacional para la emergencia de los propios DisabilityStudies) nos demuestra que los potenciales efectos sociales devaluados asociados a la lectura social de una portación de eso llamado estigma físico, expresan todo un lenguaje de relaciones entre el cuerpo y las identidades sociales. En este proceso de estigmatización, la idea de hombre normal y sus expectativas normativas esperadas, no dejan de ser testigo de la reproducción de los valores sociales considerados importantes y deseables en un momento histórico particular y en un contexto acotado. Por ejemplo, Goffman señala que en el caso de sociedad norteamericana de los años 60 , esta concepción de hombre/cuerpo "normal" obedecía a una concepción médica y burocrática de la humanidad.

También en esta dirección, los trabajos de Miche Foucault $(2007,1996)$ nos enseñan que eso llamado deficiencias no puede ser considerado algo no interesante de ser analizado desde una perspectiva crítica de la discapacidad. La deficiencia y el déficit son construcciones históricas, modernas, nacidas de la mano de la idea del individuo a corregir, que no pueden ser pensada separadamente de la producción de cuerpos dóciles para el proceso de trabajo capitalista, ni de las respuestas institucionales que naturaliza, asociadas a todo un sistema de representaciones vinculadas a las ideas de normalidad y anormalidad (Stiker, 1999). Como puente entre dichas nociones, conceptos como el de ideología de la normalidad (elaborado por el grupo de investigación de la Universidad Nacional de Entre Ríos dirigido por Ana Rosato a partir de los planteos de Mike Oliver (representante fundacional del modelo anglosajón y George Canguilhem) (2009) o el de ideología de la capacidad (desarrollado por Tom Siebers, 2013), nos brindan elementos para comprender a la producción social del déficit y de la discapacidad. Ambos conceptos, al aludir a un sistema de enunciados evaluativos cuya base es el cuerpo normal o capaz (biomédicamente definido, de acuerdo a criterios de capacidad para el proceso de trabajo), y que contrapone al déficit corporal como destino social negado, tributario de lástima y/o desprecio, permiten dilucidar las relaciones de dominación implícitas en la percepción de los cuerpos sociales. Es decir, el analizar y deshacerlos modos de clasificar a los cuerpos y las etiquetas para nombrarlos, constituyen un ejercicio nodal para visibilizar la discapacidad como cuestión política.

Este ejercicio y la construcción de herramientas teóricas que nos permitan Ilevarlo adelante, constituyen un elemento fundamental a retomar cada vez que estudiamos eso vagamente Ilamado discapacidad y deficiencia.

Y esto es necesario ya que básicamente, como bien indica el antropólogo e historiador francés Henri JakquesStiker: "No existe discapacidad, ni discapacitado, fuera de construcciones culturales y sociales precisas; no hay una actitud hacia la discapacidad fuera de una serie de referencias sociales y construcciones" (Stiker, 1999, p. 14).

Discapacidad y deficiencia no pueden ser pensadas de modo separado, tal como nos proponía el modelo social anglosajón en sus inicios ya que ambas se encuentran "definidas en un contexto socio-político específico y en un sistema de relaciones sociales" (Anastasiou y Kauffman, 2013, p. 448). De esta forma es atinado decir que la discapacidad tiene mucho que ver con el cuerpo y con eso llamado deficiencia, precisamente porque los mismos son construcciones políticas.

\subsection{Toda deficiencia es política}

Afirmar que la deficiencia es política podría llevar a realizar múltiples argumentaciones. Nos interesa detenernos aquí en dos aspectos que mencionábamos al inicio del texto que caracteriza a las miradas médicas de la discapacidad ${ }^{3}$ actualmente dominantes en nuestro mundo social: la reducción de la deficiencia a un asunto biomé-

3 Las mismas, tal como señala la socióloga argentina radicada en México Patricia Brogna (2009) pueden ser clasificadas en una visión médico-reparadora y visión normalizadora-asistencialista. 
dico e individual y la lectura de la misma como hecho patético, doloroso, digno de lástima.

Respecto al primer planteo, como venimos desarrollando, diremos nuevamente que el déficit, si puede tener que ver con lo médico y con la salud, no se reduce a este punto (Brogna, 2009). Reflexionar sobre la idea moderna de déficit, entendido como tal una falla o falta corporal nos lleva necesariamente a problematizar eso que en nuestras sociedades modernas, capitalistas, occidentales, se comprende por cuerpo normal, o, eso que podemos Ilamar siguiendo a Pierre Bourdieu (1991) cuerpo legítimo (para enfatizar como sugeríamos antes con la división social del trabajo). La configuración de la categoría "déficit", como señalábamos anteriormente recordando a Foucault (2007), visibiliza un proceso histórico de normalización que configura en el siglo XVIII una serie de discursos, prácticas, saberes e instituciones respecto al cuerpo sano-normal. Precisamente, y en plena sintonía con los planteos del modelo social de la discapacidad, ese cuerpo es aquel que reúne las disposiciones corporales necesarias para ser dócil y útil para el proceso de trabajo capitalista. El cuerpo legítimo es un cuerpo flexible, productivo y presuntamente independiente (Scribano, 2009). Aquellos cuerpos que escapen a estas disposiciones formarán parte de los individuos a corregir, dando origen a los diferentes déficits contemporáneos (ceguera, sordera, deficiencias motrices, intelectuales) (Foucault, 2007). Los mismos serán excluidos del discurrir de la vida social general e incluidos en dispositivos segregados. En este proceso, el Estado, como observador y garante de la reproducción del modo de producción capitalista, otorga el poder simbólico al modelo médico de la discapacidad, que a través de la ideología de la normalidad (Rosato et al, 2009) o de la capacidad (Siebers, 2013), concreta dicha naturalización, la cual es sedimentada en forma de esquemas de percepción (o habitus), en el sentido común, en los medios, en las instituciones. La certificación estatal de la discapacidad, con el porcentaje de invalidez a partir de una presunta incapacidad corporal-laboral, reduce a la disca- pacidad a la portación de un cuerpo improductivo, tributario de ayuda médica y/o social (Joly, 2007; 2008). Es por esto que, como afirmajoly (2007), la discapacidad "es una construcción social al servicio de la economía" ya que las propias políticas de Estado basadas en una concepción de la discapacidad como tragedia médica individual (Oliver, 1998) producen y gestionan la exclusión de las personas con discapacidad. El cuerpo discapacitado, estatal y médicamente certificado, se convierte en "una visa" (Venturiello, 2013) para la ilegitimidad social (Fassin, 2003). La deficiencia, en tanto potencial garantía de "discapacidad", de "invalidez laboral", convierten, potencialmente, a su portador, en un "pobre merecedor", en un agente imposibilitado de ejercer la ética del trabajo y, por ello, beneficiario de ciertas ayudas sociales (como una pensión por ejemplo) (Rosato et al, 2009). Como podemos notar estos planteos son plenamente complementarios y van en sintonía con los realizados por autores del modelo social anglosajón tradicional como Mike Oliver o Colin Barnes.

En tanto, las emociones despertadas por el déficit y las respuestas negativas que potencialmente genera en nuestras sociedades contemporáneas, tambiénexpresan otro fenómeno político, asociado a la regulación de los cuerpos actual: la mercantilización del cuerpo sano-bello (Bustos García y Sieglin, 2010). Desde la publicidad y los medios, pero también desde el saber médico, se nos promete que si nos acercamos al cuerpo sano-bello, seremos más felices, más plenos. Asimismo, se nos convence de que el acercamiento a tal ideal es el resultado de una decisión individual asociada al estilo de vida que elegimosdesarrollar. La capacidad de escoger nuestro modo de vida, dentro de la sociedad de consumo constituyeuna vara que estratifica subjetividades. Todos los ingredientes socialesque condicionan nuestro modo de vida (y que no elegimos) son desdibujadosa través de la ilusión de un ciudadano que gestiona su destino. La arbitrariedad de quedar dentro o fuera de una sociedad endémicamente insegura y excluyente, se convierteen una responsabilidad individual de 
"amoldarse" a los requisitos delcuerpo sano-bello (Castel, 1997). Es por esto que este ideal de cuerpo capaz no es sólo un ideal estético sino también moral (Murphy, 1991) y con consecuencias en la estratificación social (Ferrante, 2013).

Esta característica de nuestras sociedades contemporáneas llevan a caracterizarlas como tiranías estéticas (Hughes y Paterson, 2008) o de la perfección (Glassner, 1992). En las mismas los sujetos intentan estar máscerca de ese parámetro de cuerpo ideal que describíamos anteriormente.

La apariencia corporal y el rendimiento funcional de las personasdevienen, entonces, empresas que demuestran nuestra capacidad de auto-gobierno y canalizan nuestras ansias de reconocimiento social (Ferrante, 2013). En un contexto como este, la deficiencia no puede significar más que un antivalor. En primer lugar, significa el cuestionamiento a la presunta independencia (a partir de su vinculación a la idea de enfermedad y por las propias barreras sociales impuestas). En segundo lugar, debido a los procesos de estigmatización es un cuerpo legítimamente improductivo. En tercer lugar, es un cuerpo que en términos generales escapa a los parámetros de belleza establecidos. En este entramado, tal como señala Harlan Hahn, el cuerpo discapacitado genera en el hombre sin discapacidad una ansiedad estética: el temor a la muerte social y a la propia vulnerabilidad (Haller, 2010).

Así, es posible afirmar que la deficiencia y la discapacidad nos develan los valores fundamentales de nuestras sociedades contemporáneas y las estrategias sociales esgrimidas para dar respuesta a la disponibilidad diferencial de los cuerpos individuales (Albrecht, 2014; Scribano, 2007). Es en este sentido que decimos que por ello la deficiencia y la discapacidad son cuestiones políticas.

\subsection{La discapacidad: ¿nada personal?}

Ahora bien, afirmar que estos elementos son cuestiones políticas no debe ser entendido como que necesariamente la deficiencia y la discapacidad, en todo contexto y en todo agente social, impliquen la interiorización exitosa de la dominación. Precisamente, asumir al cuerpo como cuestión política no significa asumir que únicamente el mismo sea el lugar de la dominación, sino también de la creación y posibilidad de transformación social, ya que los propios agentes sociales, son los que recrean o no la dominación a través de sus prácticas (Bourdieu, 1999). Si lo social está inscripto en los cuerpos en forma de habitus, de esquemas de percepción, pensamiento y acción, al constituir soportes para la acción los mismos no son entelequias fijas, sino dispositivos confrontados en cada situación (Bourdieu, 1991).

Pero antes de seguir avanzando en esta dirección, podemos indicar que este asunto nos pone de manifiesto otro problema que se puede dilucidar en los planteos fundacionales del modelo social anglosajón respecto al supuesto de "opresión" que se maneja. Veíamos anteriormente que desde esta teoría se creía que la portación de la deficiencia homologaba las condiciones de vida de las personas discapacitadas al modo de un grupo oprimido (Shakespeare, 2013; Corker, 2008). En función de la misma se pensaba que tal opresión era generada específicamente por el modo de producción capitalista (Abberley, 1998; Oliver, 1998). El mismo, a partir de una definición de cuerpo capaz -definido de acuerdo a criterios de rentabilidad económica- excluye a los cuerpos discapacitados de la división social del trabajo, segregándolos de la vida general y/o colocándolos en dispositivos de inclusión excluyente (Almeida, 2009). Como resultado de este proceso, se consideraba que las personas con discapacidad podían ser consideradas miembrosde una clase social, que homogéneamente experimentarían idéntica discriminación en sus interacciones cotidianas, semejantes desventajas en la estratificación social y en el espacio físico (Venturiello, 2013; Ferreira, 2008).

Desde este planteo, la resolución de la opresión que sufren las personas con discapacidad se relaciona a la remoción de los aspectos estructurales y considerados "objetivos" que crean la desventaja social de este grupo. Desde este esquema, 
derribadas las barreras que fundan la discapacidad, la deficiencia en sí misma no significaría ningún problema para sus protagonistas (Finkelstein, 1980; Oliver, 1996). En pos de garantizar este horizonte, desde las ciencias sociales y desde la lucha por los derechos, los aspectos experienciales de la discapacidad no revestían ningún valorya que se consideraba que carecían de valor político (Ville et al, 2014; Shakespeare, 2013). Así, tal como indican Isabel Ville, EmanuelleFillion y Jean-François Ravaud (2013):

Desde esta perspectiva, cualquier lectura de la experiencia subjetiva de la discapacidad era vista con suspicacia; podía fortalecer la segregación y la discriminación y la idea de que la aparición de una deficiencia constituía una inevitable tragedia, que las personas son víctimas pasivas. (Ville et al, 2014 p. 120).

De este modo, podemos indicar que detrás del rechazo a incorporar la experiencia de la discapacidad en el modelo británico tradicional es posible detectar tres prejuicios interconectados. En primer lugar, devela un preconcepto que opone "lo objetivo" (la opresión materializada en diversos aspectos extra-corporales, impuestos sobre las personas discapacitadas), a "lo subjetivo" (la experiencia de esa opresión y de la deficiencia en general) en donde lo político estaría ausente (Ville et al, 2014).

En segundo lugar, supone que para todas las personas con discapacidad las deficiencias no constituyen un problema en sí mismo. Autoras y autores como Jenny Morris, Sally French, Liz Crowo Robert Murphy, en los años 90, señalaron pioneramente la importancia de la experiencia de la deficiencia en la vivencia de la discapacidad (Shakespeare, 2013; Ville et al, 2014).

En esta dirección, Crow en 1992 indicaba:

Como individuos, la mayoría de nosotros simplemente no podemos pretender que nuestra creencia con los deterioros son irrelevantes porque afectan cada parte de nuestras vidas. Debemos encontrar la manera de integrar en nuestra propia experiencia e identidad por el bien de nuestro bienestar físico y emocional, y, posteriormente, por nuestra capacidad de trabajar contra la discapacidad (Crow citada en Shakespeare, 2013, p. 217).

En la misma dirección, el antropólogo norteamericano con una discapacidad motriz adquirida Murphy en TheBodySilent, en 1987, recuperando a Goffman y a partir de su propia vivencia de adquisición de una cuadriplejía, narra cómo la experiencia de la deficiencia es inseparable de la discapacidad y que por ello es una postal de las discriminaciones experimentadas, pero también resistidas por esta minoría. El autor relata cómo en su caso la deficienciageneró, en un primer momento,un daño al sí mismo por la pérdida de la autonomía corporal en un mundo histórico en el cual la independencia es un factor que jerarquiza a los agentes sociales (Murphy, 1991). Sin embargo, con el tiempo, el agente describe la estrategia de la desencarnación para dar respuesta y cuestionar esa herida y las respuestas negativas. Es decir, aquí vemos cómo la experiencia no está separada de los procesos de dominación, pero también, como los mismos no son destinos predeterminados, sino que los propios agentes sociales erigen sus energías sociales para cuestionar los mismos.

Como podemos advertir, entonces, reconocer la importancia de la experiencia de la deficiencia o aún que la misma signifique en sus primeros momentos una auténtica tragedia que exige reorganizar el sí mismo y la biografía personal, no implica asumir que necesariamente la misma deba adquirir siempre esta connotación.

Es aquí que debemos desarrollar un tercer elemento antes apenas mencionado. No puede darse a la infravaloración u opresión de las personas con discapacidad como algo pre-dado (Shakespeare, 2013). Este modo de concebir a la dominación niega toda posibilidad de cuestionamiento de los agentes sociales y presta poca atención a los aspectos relacionales de este proceso. Si volvemos otra vez al clásicoEstigma deGoffman (2001)nuevamente podemos encontrar una pista interesante para no olvidar que la estigmatización no alude a un lenguaje de atributos, sino de relaciones socia- 
les, en donde ese etiquetado como portador de un estigma físico, es calificado exitosamente como tal por otro social. Las opciones que se abren en los encuentros mixtos -entre personas con discapacidad y sin ella-, por poner sóloun ejemplo, contemplan muchas variables: la posibilidad de manejo de la información por parte del estigmatizable, la mirada del otro -estigmatizante o reconocedora-.

Si introducimos este ejemplo a la teoría de la dominación de Pierre Bourdieu $(1999,1991)$ podemos agregar que, entonces, la dominación no es un mecanicismo garantizado a priori. La misma es el resultado de la incorporación exitosa de la violencia simbólica, es decir, de un arbitrario social vuelto naturaleza (en este caso: la reducción de la discapacidad a un déficit individual que imposibilita para la vida social). Desde este esquema, la dominación nunca está asegurada, puede ser aceptada, cuestionada, tensionada de acuerdo a una serie de variables que singularizan la experiencia de la discapacidad. En este sentido, la experiencia de la discapacidad no puede ser homologada idénticamente para todas las personas que portan una deficiencia y es reduccionista sostener la idea de grupo oprimido. La discapacidad no es un atributo estático, sino que es dinámico y se construye en la interacción entre el agente y una situación social (Pantano, 1987; Venturiello, 2010). Como bien señala Brogna:

La discapacidad toma cuerpo en un espacio situacional, dinámico einteractivo entre alguien con cierta particularidad y la comunidad que lo rodea. Si lo graficáramos como sigue: sociedad-persona con discapacidad la discapacidad estaría EXACTAMENTE en el guión que las relaciona. Entendida comouna creación social, significada dentro de una situación relacional, puesta en perspectivacomo un evento situacional, la discapacidad es entonces el espacio contingente y arbitrarioque se le asigna a ese sujeto y por lo tanto la situación de desventaja aumenta o disminuyen función de su contexto social (y económico) (Brogna, 2006, p. 2).
Existen un conjunto de dimensiones tales como la clase social, el tipo de deficiencia, la edad de adquisición, el grupo familiar, la orientación sexual, el género, la religión, la participación en asociaciones de personas con discapacidad, el contexto social que particularizarán tal vivencia. No es lo mismo tener una discapacidad motriz y ser una joven de clase alta, profesional, con una familia propia constituida, que vive en Santiago de Chile o Buenos Aires, a ser una joven de la misma edad, con una deficiencia motriz similar, pero ser de clase baja, no haber terminado la educación básica, poseer escasas redes sociales vivir en el norte de Chile o de Argentina y sobrevivir a través de la mendicidad. Existen múltiples variables que se superponen a la discapacidad y que dotarán a los agentes de diferentes capitales para manejar el estigma, esbozando trayectorias sociales muy disímiles. La recuperación de tales vivencias, entonces, sociológicamente pueden ser elementos nutritivos para evidenciar la influencia de los factores contextuales en la discapacidad, para denunciar la amputación de las energías sociales particulares.

Pormenorizar la dimensión vivencial de la discapacidad, entonces no necesariamente significa negar sus aspectos macro-sociales, sino tratar de recuperar esas coloraciones singulares que nos recuerdan que existen agentes sociales, con capacidades de creación y transformación social. En todo caso, pensar que en esas narrativas borran lo social y lo político es también parte de un prejuicio que opone la observación de lo micro o de lo macro, lo subjetivo de lo objetivo.

Pensar a la experiencia como exclusivamente subjetivo conduce a pensar que el agente social es un sujeto ahistórico, cuando desde un planteo sociológico esto no es admisible. La experiencia social es uno de esos terrenos que nos demuestra la constante ambigüedad entre la sedimentación de lo social en esquemas de percepción, pensamiento y acción -filtrados diferencialmente de acuerdo a clase social, género, edad, etc.-, y la espontaneidad de la situación particular (Bourdieu, 1991). 
Desde este punto de vista, el cuerpo, en tanto pivote de la experiencia (Merleau Ponty, 1985) adquiere el papel de constituir no solo el espacio de la dominación, sino también, de la posibilidad de su cuestionamiento o fisura. La indignación y bronca contra la discriminación experimentada hacia las personas con discapacidad puede convertirse en lucha política, en intención de transformar lo dado; el potencial estigma puede devenir un orgullo, una exigencia de reconocimiento (Hughes y Paterson, 2008). Tal como señala el sociólogo argentino Adrián Scribano (2007) "el cuerpo es el locus del orden y del conflicto".

\section{DisCuSIÓN}

En este textohemos partido de la recuperación del Ilamado modelo social de la discapacidad y del rastreo de su potencia para comprender a la discapacidad como cuestión política. Caracterizamos sus aspectos fundacionales, surgidos en los años 70, y su positivo impacto en la lucha por el reconocimiento de las personas con discapacidad.

Revisando brevemente algunos datos actuales sobre las condiciones de vida de las personas con discapacidad en el mundo, arrojadas por el Informe Mundial de la Discapacidad e imposibles de ser leídos sino es de la mano de los procesos regresivos generados por el capitalismo actual, hemos indicado que en pleno 2014 el modelo social sigue siendo una herramienta fundamental para entender y explicar la persistencia de diversas formas de exclusión que afectan a las personas con discapacidad.

No obstante ello, también hemos señalado que en los planteos originales del modelo social de la discapacidad existen algunas cuestiones teóricas a ser revisadas no para anularlo, sino para fortalecer su capacidad analítica. Tal constructo, como fiel testigo de la época, incorpora algunos clásicos antagonismos modernos derivados de la oposición cuerpo/mente; naturaleza/cultura; micro/macro; subjetivo/objetivo; experiencia/sociedad. Puntualmente, aquí nos hemos concentrado en el exilio de las nociones de cuerpo y experiencia, dimensiones apartadas en los inicios de dicho modelo. Como indicamos, en los años 70 se creía que tales conceptos biologizaban y psicologizaban la discapacidad. Sin ser originales, ya que muchos autores vienen planteando estas cuestiones desde los años 90, a través de este trabajo buscamos mostrar el carácter desacertado de tales juicios. No optamos para ello el camino de desarrollar una sociología de la discapacidad o de la deficiencia(Hughes y Paterson, 2008), tal como sugieren algunos autores inscriptos en la tradición de los Disability Studies ya que consideramos que una mirada amplia puede ser más fructífera en términos teóricos. Las ciencias sociales y las humanidades, y no solamente la sociología, nos brindan elementos para esbozar múltiples recorridos para abordar esta cuestión. Alguno de los mismos los hemos transitado muy sucintamente por este texto. Podrían abrirse otras lecturas e inclusive otros diálogos con disciplinas como las humanidades médicas o el derecho y es seguro que esos intercambios enriquecerían el punto de vista.

Cuerpo y experiencia, o también, cuerpo/experiencia ${ }^{4}$ (ya que es imposible pensar al primero sin un sujeto que lo habita, y es impensable la segunda si no es encarnada en una corporalidad) son productos sociales atravesados por relaciones de dominación arbitrarias, históricas. La discapacidad es una de esas formas de dominación. La deficiencia, o mejor, el cuerpo deficiente, tampoco escapa a esta producción socio-política. La misma es el resultado de la clasificación de los cuerpos sociales en función de una ideología de la normalidad (Rosatoet al, 2009) que naturaliza en la forma de falla, falta o incorrección corporal/intelectual un modo de dominación particular.Es por esto que todo análisis crítico de la discapacidad debe incluir una problematización al respecto. La división deficiencia/ discapacidad, presente en los planteos fundacionales del modelo social debe ser tensionada. Aceptar el carácter político del cuerpo no lleva a medica- 
lizar la discapacidad, sino a ir un paso más atrás en la argumentación teórica. A su vez, reconocer esta dimensión, no implica incorporar un determinismo. El cuerpo es espacio de la dominación y de la creación de lossujetos. En el caso de la discapacidad esto implica que en un mundo social en el cual se valoran, de acuerdo a la división social del trabajo, los cuerpos útiles para la rentabilidad económica, poseer una deficiencia significará potencialmente un estigma o una tragedia individual. Pero que efectivamente lo constituya dependerá de las diversas variables que singularizan la experiencia de la discapacidad en las que inciden los factores socioeconómicos y culturales (Venturiello, 2013), a través de las cuales se esbozará a nivel individual, un mundo entre todos los posibles. Ese mundo no necesariamente será el de la interiorización del drama de la impotencia, de asunción del traje del mendigo, sino que también podrá ser el del orgullo, la vida que vale la pena ser vivida, y el cuestionamiento a la dominación.

Eneste sentido, consideramos que ensayar miradas que entiendan al cuerpo y a la experiencia, como construcciones políticas, en su doble condición de expresión de procesos de dominación, pero también como posibilidad de cuestionamiento, reproducción o tensión de los mismos, puede brindarelementos para comprender la complejidad de la discapacidad como relación de dominación. Esta alternativa es una buena salida para escapar a otra idea presente en los orígenes del modelo social que hemos indicado en el texto: la de grupo oprimido, que parte de un supuesto de la dominación mecanicista y que niega la posibilidad de agencia.

Más que una intención a concluir un debate o una propuesta, este texto ha tenido la intención de poner en escena la necesidad de desarrollar herramientas teóricaspara comprender cómo la discapacidad, comprendida como un elemento más de las políticas de los cuerpos(Scribano, 2009), se transforma -o no- en modo de dominación que niega el pleno estatuto humano y la dignidad de aquellos cuerpos que escapan a la normatividad única.

\section{REFERENCIAS BIBLIOGRÁFICAS}

Abberley, P. (1998). Trabajo, utopía e insuficiencia, en Barton, Len (comp.) Discapacidad y sociedad. Madrid: Ediciones Morata. P. 77-96.

Albrecht, G. (2014) Préface, en Ville, I., Fillion, E, Ravaud, J. F.Introducción à la sociologie du hándicap. Histoire, politiques et expérience. Belgique: De Boeck. p. 9-13.

Almeida, M. E. (2009). "Exclusión y discapacidad: entre la redistribución y el reconocimiento", en Angelino, A. y Rosato, A. (Coords.) Discapacidad e ideología de la normalidad. Desnaturalizar el déficit. Buenos Aires: Noveduc. p. 215-230.

Anastasiou, D. y Kauffman, J. (2013). "The Social Model of Disability: Dichotomy between Impairment and Disability". Journal of Medicine and Philosophy 38, 441-459.

Barnes, C. (1998). "Las teorías de la discapacidad y los orígenes de la opresión de las personas discapacitadas en la sociedad occidental". En Discapacidad y sociedad, comp.porLenBarton. Madrid: Ediciones Morata. p. 59-76.

Bauman, Z. (1999). Trabajo, consumismo y nuevos pobres. Barcelona: Gedisa.

Bourdieu, P. (1991).El sentido práctico. Madrid: Taurus

Bourdieu, P. (1999). Meditaciones Pascalianas. Barcelona: Anagrama.

Bregain, G. (2013). "An entangled perspective on disabilityhistory: The disabilityprotests in Argentina, Brazil and Spain, 19681982" enBarsch, S., Klein, A. and Verstraete, P. (dir.), The ImperfectHistorian: Disability Histories in Europe. Frankfurt am Main: Peter Lang. p. 133-154.

Brogna, P. (2009). “Las representaciones de la discapacidad: la vigencia del pasado en las estructuras sociales presentes". En Visiones y revisiones de la discapacidad, comp.Brogna, P. México: Fondo de Cultura Económica. p.157-187.

Brogna, P. (2006). "El nuevo paradigma de la discapacidad y el rol de los profesionales de la rehabilitación". El Cisne, Abril.

Bustos García, B. A. y Sieglin, V. (2010). "La construcción de la otredad a travésdel cuerpo: paradigmas de análisis en torno al cuerpo discapacitado", en Brenda A., BustosGarcía, y M. L., Martínez Sánchez (comps.), Cuerpo y discapacidad: perspectivas latinoamericanas. México: Universidad Autónoma de Nuevo León. p. 13-54.

Castel, R. (1997). La metamorfosis de la cuestión social. Una crónica del asalariado. Buenos Aires: Paidós.

Corker, M. (2008). "Diferencias, fusiones y bases. ¿Son estos los límites de la representación teórica "precisa" de las experiencias de las personas con discapacidad?" en Barton, L. (comp.). Superar las barreras de la discapacidad. Madrid: Morata, p. 124-141

Fassin, D. (2003). "Gobernar por los cuerpos políticas de reconocimiento hacia los pobres y los inmigrantes en Francia". Cuadernos de Antropología Social, 17 (3), 49-78.

Ferrante, C. (2013). "Cuerpo, discapacidad y menosprecio social. Ajustes y resistencias a las tiranías de la perfección". En Estado, Discapacidad y Justicia comp. Emiliano José Jorge y Gerardo Andrés D’Ugo. Buenos Aires: Infojus, Ministerio de Justicia de 
la Nación. p. 99-122. Disponible en: https://www.academia. edu/3650581/Cuerpo_discapacidad_y_menosprecio_social._ Ajustes_y_resistencias_a_las_tiranias_de_la_perfeccion. Recuperado 24 de junio de 2014.

Ferrante, C. (2014). Usos, posibilidades y dificultades del modelo social de la discapacidad. Revista Inclusiones. Revista de Humanidades y Ciencias Sociales, 1 (3), 33-55.

Ferreira, M. A. V. (2008). Una aproximación sociológica a la discapacidad desde el modelo social: apuntes caracterológicos. Revista Española de Investigaciones Sociológicas, 124: 141-174.

Finkelstein, V. (1980). Attitudes and DisabledPeople: Issuesfor Discusión. Londres: World Rehabilitation Fund

Foucault, M. (2007). Los anormales, Buenos Aires: FCE.

Foucault, M. (1996). Historia de la locura en la época clásica. Buenos Aires, Fondo de Cultura Económica.

Glasner, B. (1992). Bodies: the tiranny of perfection. Los Angeles: Lowell House.

Goffman, E. (2001). Estigma. La identidad deteriorada. Buenos Aires: Amorrortu.

Haller, B. A. (2010) "Pity as opression in the Jerry Lewis Telethon". In Representing Disability in an ableist world. Essays on mass media. Louiville, K.Y: The Advocado Press. p .137-152.

Hanna, W. y Rogovsky, B. (2008) "Mujeres con discapacidad: la suma de dos obstáculos" En Barton, Len (comp.) Superar las barreras de la discapacidad. Madrid: Ediciones Morata.

Hughes, B. y Paterson, K. (2008). "El modelo social de discapacidad y la desaparición del cuerpo. Hacia una sociología del impedimento". En Barton, Len (comp.) Superar las barreras de la discapacidad. Madrid: Ediciones Morata. p. 107-123.

Joly, E. (2008), "Discapacidad y empleo. Por el derecho a ser explotados", Le Monde Diplomatique, Buenos Aires, octubre.

Joly, E. (2007) La discapacidad: una construcción social al servicio de la economía. Disponible en: http://www.rumbos.org.ar/discapacidad-una-construccion-social-al-servicio-de-la-economiaclase-facderuba. Acceso 23-07-14.

Joly, E. y Venturiello, M. P. (2012). "Persons with Disabilities: Entitled to Beg, not to Work. TheArgentine Case" CriticalSociology, 39(3), 325-347.

Mauss, M. (1979). Sociología y Antropología. Madrid: Tecnos.

Merleau-Ponty, M. (1985). Fenomenología de la Percepción, Barcelona: Planeta Agostini

Murphy, R. (1991). The body silent. New York: Norton \& Company.

Oliver, M. (2008). Políticas sociales y discapacidad. Algunas consideraciones teóricas, en Barton, L. (comp.)Superar las barreras de la discapacidad. Madrid: Morata. p. 19-38.

Oliver, M. (1998). ¿Una sociología de la discapacidad o una sociología discapacitada?, en Barton, L. (comp.) Discapacidad y Sociedad. Madrid: Morata. p. 34-59.

OMS, Banco Mundial (2011). Informe mundial sobre la discapacidad. Ginebra: OMS.

Pantano, L. (1987). La discapacidad como problema social. Buenos Aires: EUDEBA.
Parsons, T. (1984). El sistema social. Madrid: Alianza.

Rosato, A. et al (2009). El papel de la ideología de la normalidad en la producción de discapacidad. En Ciencia, Docencia y Tecnología No 39, 87-105.

Scribano, A. (2009). Una periodización intempestiva de las políticas de los cuerpos y las emociones en la Argentina reciente. En Boletín Onteaiken, Nㅜ 7. Disponible on line: onteaiken.com.ar/ver/ boletin7/1-1.pdf区.

Scribano, A. (2007). La sociedad hecha callo: conflictividad, dolor social y regulación de las sensaciones, en Mapeando Interiores. Cuerpo, Conflicto y Sensaciones. Córdoba: CEA-UNC - Jorge Sarmiento Editor. p. 118-142.

Skliar, C. (2002). ¿Y si el Otro no estuviera ahí? Notas para una pedagogía (improbable) de la diferencia. Buenos Aires: Escuela Marina Vitte CTERA- Miño y Dávila Editores.

Shakespeare, T. (1998). Poder y prejuicio: los temas de género, sexualidad y discapacidad en Barton, L. (comp.) Discapacidad y Sociedad. Madrid: Morata. p. 205-229.

Shakespeare, T. (2013). The social model of disability, en Davis, L. (ed.) The Disability Studies Reader. New York: Routledge. Pp. 214-221.

Shakespeare, T. y Watson, N. (1996), "The body line controversy: a new direction for Disability Studies?",Disability Studies Seminar. Disponible on line en: http://disability-studies.leeds.ac.uk/files/ library/Shakespeare-The-body-line-controversy.pdf.

Siebers, T. (2013). "Disability and the theory of complex embodiment. For identity politcs in a new register." in Davis, L. (ed.) The Disability Studies Reader. New York: Routledge. P. 278-297

Stiker, H.-J. (2013) A history of disability. United States of America: The University of Michigan Press.

UPIAS (Union of the Physically ImpareidAgainst Segregation) (1976) Fundamental Principles of Disability. Londres, Union of the Physically ImpareidAgainst Segregation citadoenAbberley, P. (1998). Trabajo, utopía e insuficiencia, en Barton, Len (comp.) Discapacidad y sociedad. Madrid: Ediciones Morata. P. 77-96.

Venturiello, M. P. (2013). "Los cuerpos con discapacidad en los diferentes ámbitos sociales: espacios físicos e interacciones sociales". Ponencia presentada en las VII Jornadas de Jóvenes Investigadores, Instituto de Investigaciones Gino Germani. Disponible en: http://jornadasjovenesiigg.sociales.uba.ar/files/2013/10/eje7venturiello.pdf.

Venturiello, M. P. (2010). El habitus discapacidad a la luz de un relato de vida. Intersticios. Revista sociológica de pensamiento crítico 4 (2), 175-185.

Ville, I., Fillion, E, Ravaud, J. F. (2014) Introducción à la sociologie du hándicap. Histoire, politiques et expérience. Belgique: De Boeck.

Vite Pérez, M. Á. (2012) La discapacidad en México entendida desde la vulnerabilidad social". Polis8 (2), 1-22.

Wilson, D. (2004). "Fighting polio like a man." pp. 119-133 in Smith, B. and Hutchison, B. (eds.) GenderingDisability. New Jersey: RutgersUniversityPress. 